\title{
Improvement of Inset Fed Microstrip Antenna's Pefromances with Types of Metamaterials at 28 $\mathrm{GHz}$
}

\author{
Maisarah Abu, Siti Adlina Md Ali, Siti Normi Zabri
}

\begin{abstract}
This paper presents improvement of insert feed microstrip antenna with types of types of metamaterials. The antenna and the metamatrials were printed on a thin substrate, Rogers RT5880 with $0.254 \mathrm{~mm}$ thickness. Two types of metamaterials were introduced; Artificial Magnetic Conductor (AMC) and Frequency Selective Surface (FSS). The metamaterials were placed on the bottom of the antenna with no gap. Four cases were analyzed; antenna alone, antenna with AMC, antenna with FSS and antenna with multi-layer of FSS-AMC. Performances of the antenna were evaluated in terms of return loss, useful bandwidth and realized gain. The resonating frequency was shifted but still operate well at $28 \mathrm{GHz}$. Improvements in useful bandwidth from antenna alone and as it worked with all types of metamaterials. The realized gain was effectively improved from $1.76 \mathrm{~dB}$ up to $6.16 \mathrm{~dB}$ for the fourth cases. The design of insert feed microstrip antenna with types of thin metamaterials can be applied as a flexible applications in advanced sensors.
\end{abstract}

Keywords : insert feed microstrip antenna, metamaterias, amc, fss, and gain.

\section{INTRODUCTION}

Microstrip patch antennas have been extensively used for a long time due to their attractive features; light weight, low profile and ease of fabrication [1-3]. Thus, these antenna are better to use for applications like flexible applications in advanced electronics [4-8]. However, the microstrip patch antenna usually suffers from several drawback; low efficiency, narrow bandwidth and less gain.

The four most popular feed techniques used are the insert feed line, coaxial probe, aperture coupling and proximity coupling [9-10]. Aperture feed, proximity feed and coaxial probe were difficult to fabricate; soldering, drilling and alignment needed. Multi-layer substrates needed for both aperture feed and proximity feed thus contribute to high cost.

Revised Manuscript Received on July 22, 2019.

* Correspondence Author

Maisarah Abu, Centre of Telecommunication Research and Innovation (CeTRI), Faculty of Electronic and Computer Engineering (FKEKK), Universiti Teknikal Malaysia Melaka, Hang Tuah Jaya, 76100 Durian Tunggal, Melaka, Malaysia. Email: maisarah@utem.edu.my

Siti Adlina Md Ali, Centre of Telecommunication Research and Innovation (CeTRI), Faculty of Electronic and Computer Engineering (FKEKK), Universiti Teknikal Malaysia Melaka, Hang Tuah Jaya, 76100 Durian Tunggal, Melaka, Malaysia. Email: khalif5086@yahoo.com

Siti Normi Zabri, Centre of Telecommunication Research and Innovation (CeTRI), Faculty of Electronic and Computer Engineering (FKEKK), Universiti Teknikal Malaysia Melaka, Hang Tuah Jaya, 76100 Durian Tunggal, Melaka, Malaysia. Email: normi@utem.edu.my
In terms of reliability, insert feed line was better as compared to the others. Hence insert feed line is used because the substrate thickness can be reduced so that the bandwidth is enhanced. In addition harmonics can be fully suppressed.

Some parameters are take into consideration to identify the input impedance of these antennas such as geometrical shape, dimensions, the substrate properties, the location and type of feeding [11]. Hence, a group of antenna parameters will be attuned to accomplish the "best" geometry for matching of a certain resonance.

The drawback of microstrip antenna can be minimized as made it in array. An array structure also increased the gain and directivity of the antenna [12-14]. However, array configurations occupied space and leads to increase the dimensions, contributed to higher costs. The limitations of arrays was solved by the introduction of metamaterials to the antenna array. Artificial Magnetic Conductor (AMC) and Frequency Selective Surfaces (FSS) was a types of metamaterials in ordedr to improve the radiation parameters of microstrip antenna; bandwidth, gain, directivity, front-to-back ratio and reduced surface waves [15-20].

Various types of metamaterial structures; AMC and FSS have been developed to behave as PMC for microstrip antenna. Previous literature show that gain enhancement of microstrip antenna was limited by using either AMC or FSS. Therefore, this work proposes the differ technique to reduce the limitation of the the microstrip antenna.

This works proposed the incorporated between the antenna with both types of metamaterials; AMC and FSS. All types of metamaterials were placed on the bottom of the antenna to reduce the limitation of the microstrip antenna. Hence, the multi-layer of FSS-AMC was proved to increase the highest gain as compared to the incorporation between the antenna with either AMC or FSS alone. The design of insert feed microstrip antenna with types of thin metamaterials can be applied as a flexible applications in advanced electronics.

\section{RESEARCH METHOD}

\section{A. Inset fed microstrip patch antenna}

Basically, microstrip patch antenna consist of radiating element and a ground plane separated by a dielectric substrate as shown if Figure 1. A rectangular patch of length $\left(L_{p}\right)$ and width $\left(W_{p}\right)$ was designed. The patch is cut at a depth $(g)$. Then inset feed of length $(d)$ and width $(w)$ was formed. 
The port is defined at the end of the feed line. All the dimensions of the antenna was calculated based on equation (1) to equation (4).

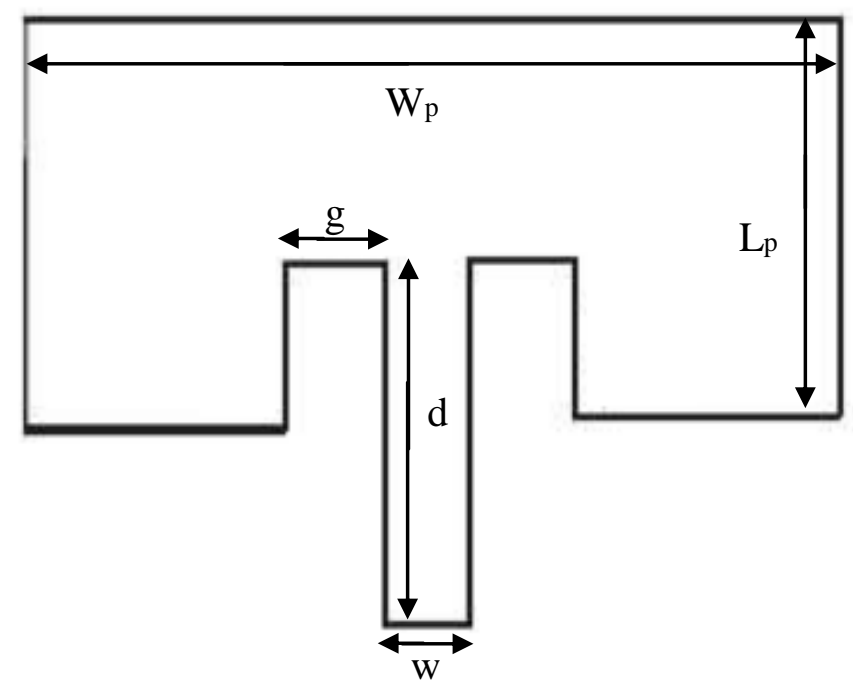

Fig. 1. Microstrip inset fed line.

The width is given by:

$$
w=\frac{e}{2 f_{0}} \sqrt{\frac{2}{\varepsilon_{r}+1}}
$$

The effective dielectric constant for the case of $(w / h>1)$ is given by

$$
\varepsilon_{\text {eff }}=\frac{\varepsilon_{r}+1}{2}+\frac{\varepsilon_{r}-1}{2}\left[1+12 \frac{\hbar}{w}\right]^{\frac{1}{2}}
$$

The extension of patch length due to fringing effects can be determined by

$$
\Delta L=412 h \frac{\varepsilon_{\alpha f f}+0.3\left(\frac{W}{h}+0.264\right)}{\varepsilon_{\alpha f f}-0.258\left(\frac{W}{h}+0.8\right)}
$$

The effective length of patch after taking into fringing effect can be calculated by

$$
L=\frac{\lambda_{D}}{f_{0} \sqrt{\varepsilon_{r a f f}}}-2 \Delta L
$$

The design of inset fed microstrip antenna was started with rectangular microstrip patch as radiating element. Therefore, the pacth was fed by a 50 inset fed microstrip line. Thus was a simple model and easy match by adjusting the inset fed location. Figure 2 shows the inset fed microstrip antenna, printed on thin substrate, Rogers RT5880 with permittivity of 2.2. The antenna was resonated at $28 \mathrm{GHz}$ while the port was defined at the end of the feed line. Meanwhile Table 1 illustrates the physical dimensions of $28 \mathrm{GHz}$ inset fed microstrip antenna.

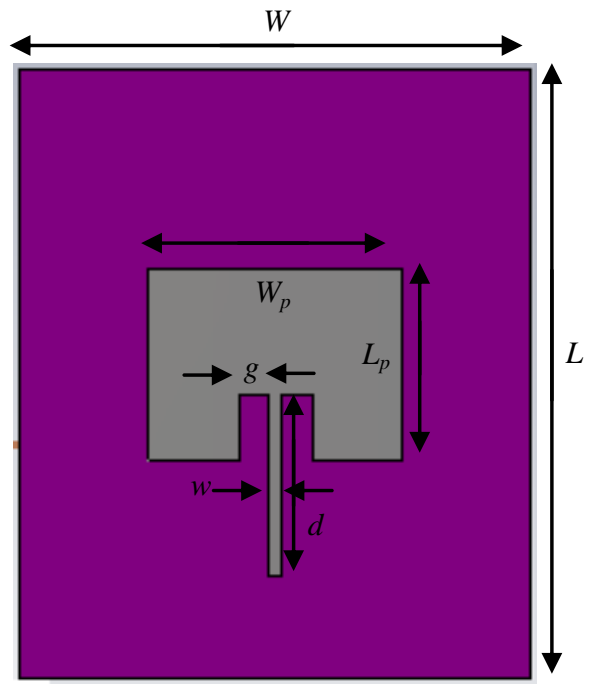

Fig. 2. Inset fed microstrip antenna structure

Table- I: Physical dimensions of inset fed microstrip antenna

\begin{tabular}{|l|c|}
\hline & Dimension (mm) \\
\hline Thickness of the substrate, $h$ & 0.25 \\
\hline Length of the patch, $L_{p}$ & 3.92 \\
\hline Width of the patch, $W_{p}$ & 4.50 \\
\hline Substrate length, $L$ & 10.73 \\
\hline Substrate width, $W$ & 9.00 \\
\hline Inset fed width, $w$ & 0.25 \\
\hline Inset fed length, $g$ & 3.20 \\
\hline Inset fed gap, $g$ & 0.52 \\
\hline
\end{tabular}

\section{B. AMC and FSS}

AMC and FSS were designed based on square schematic. Basically AMC consists of patch, substrate and ground plane at the bottom side. Hence described by reflection phase and magnitude. Differ to FSS, there was no ground plane at the back of the substrate, characterized by transmission and reflection coefficients. Figure 3 shows the square AMC thus assigned impedance equal to that of parallel $L C$ circuit and has high surface impedance at resonant frequency.

The inductance $(L)$, capacitance $(C)$, frequency response $\left(f_{r}\right)$ and bandwidth $(B W)$ were determined as in Equation (5) to equation (8).

$$
\begin{gathered}
L=\mu_{O} h \\
C=\frac{w \varepsilon_{0}\left(1+\varepsilon_{r}\right)}{\pi} \cosh ^{-1}\left(\frac{2 w+g}{g}\right)
\end{gathered}
$$




$$
\begin{gathered}
f_{r}=\frac{1}{2 \pi \sqrt{L C}} \\
B W=\frac{1}{m_{0}} \sqrt{\frac{L}{C}}
\end{gathered}
$$

where, $\quad \eta_{O}$ is free space impedance $\varepsilon_{O}$ is free space permittivity $\mu_{O}$ is free space permeability $h$ is thickness of the substrate $w$ is width of the patch $g$ is gap between adjacent patches

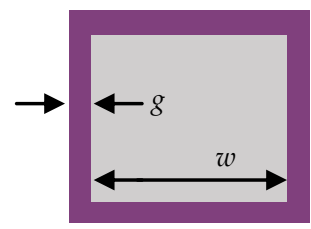

(a)

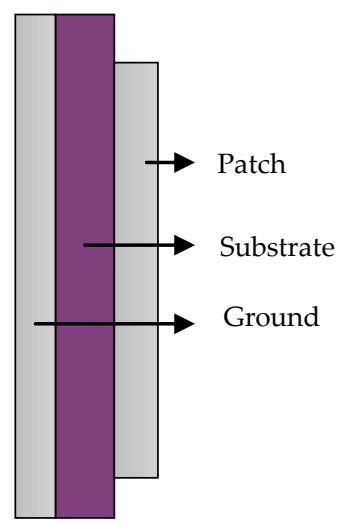

(b)
Fig. 3. Basic AMC structure; (a) front view and (b) side view

Figure 4 shows the designs of metamaterials for a unit cell simulation designed and prototype of array structure. Both AMC and FSS were designed based on square shape. There was four $1.54 \mathrm{~mm}$ square patches printed at the edge of the 3.6 $\mathrm{mm}$ square substrate. Full ground plane was attached at the back of the substrate for AMC. Meanwhile, FSS patch was designed as $0.17 \mathrm{~mm}$ square ring and no laminated ground plane at the back. Both AMC and FSS were designed on Rogers RT 5880 substrate, same the antenna with thickness of $0.25 \mathrm{~mm}$. All of the physical dimensions for both AMC and FSS are shown in Table II and Table III respectively.

Table- II: Physical dimensions of AMC structure

\begin{tabular}{|l|l|}
\hline AMC & Dimension (mm) \\
\hline Gap between patches, J & 0.52 \\
\hline Length of the square patch, K & 1.54 \\
\hline Length of the square substrate, L & 3.60 \\
\hline
\end{tabular}

Table- III: Physical dimensions of FSS structure

\begin{tabular}{|l|l|}
\hline FSS & Dimension (mm) \\
\hline Width of the square ring patches, X & 0.17 \\
\hline Length of the square patch, Y & 2.90 \\
\hline Length of the square substrate, Z & 3.60 \\
\hline
\end{tabular}

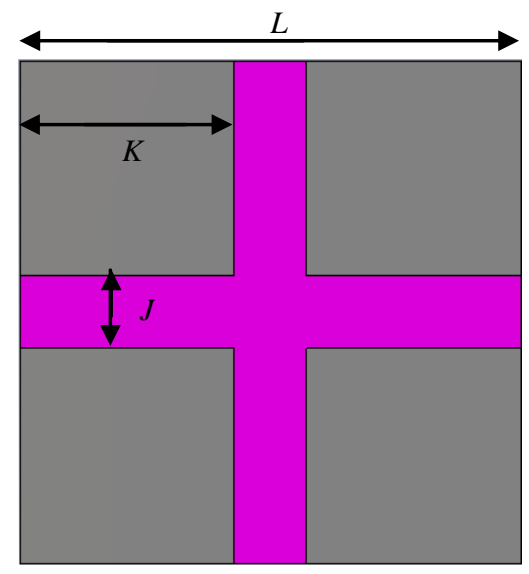

(a)

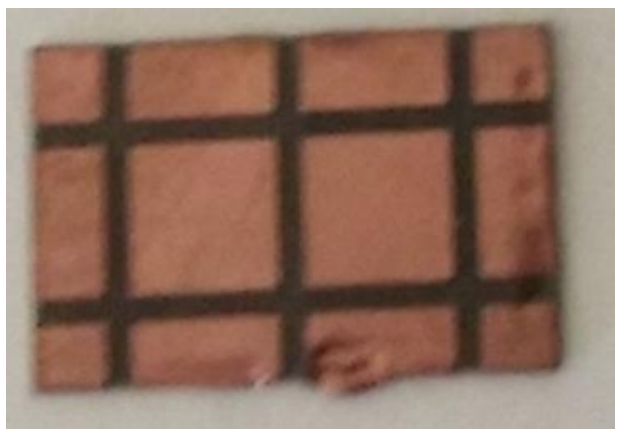

(b)

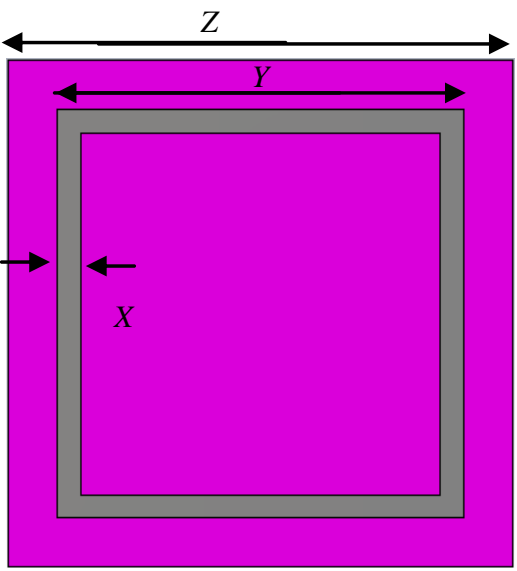

(c)

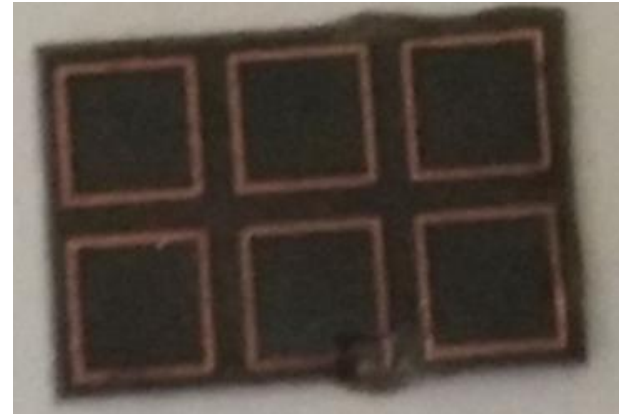

(d) 
Fig. 4. Designs of metamaterials; (a) AMC unit cell, (b) 3 by 2 arrays of AMC prototype, (c) FSS unit cell and (d) 3 by 2 arrays of FSS prototype

\section{RESULTS AND ANALYSIS}

\section{A. Inset fed microstrip patch antenna}

Figure 5 plots the return loss of the inset fed microstrip antenna both for simulation and measurement. At $28 \mathrm{GHz}$, the antenna operated about $-21.89 \mathrm{~dB}$ of return loss for earlier design in simulation. Meanwhile the return loss was better as in measurement which was around $-39.67 \mathrm{~dB}$ at $28 \mathrm{GHz}$. However, the useful bandwidth of the antenna was degraded as in measurement which was around $6.81 \%$, compared to

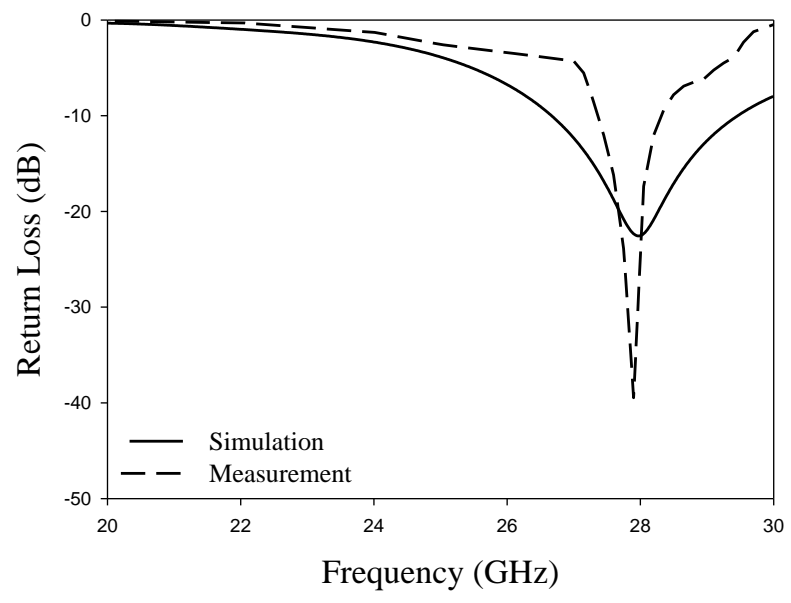

Fig. 5. Return loss of inset fed microstrip antenna

\section{B. AMC and FSS}

AMC structure was characterized by reflection phase and magnitude as in Figure 6. The reflection magnitude was -0.11 $\mathrm{dB}$ approximately to 0.97 at $28 \mathrm{GHz}$. Meanwhile, the reflection phase was varied from $180^{\circ}$ to $-180^{\circ}$. At $\pm 90^{\circ}$, the bandwidth of the structure was defined. The frequency was laid from $26.21 \mathrm{GHz}$ to $29.57 \mathrm{GHz}$ which contributed around $12 \%$ useful bandwidth. The AMC structure was resonated at $28 \mathrm{GHz}$ as referred to $0^{0}$ of reflection phase.

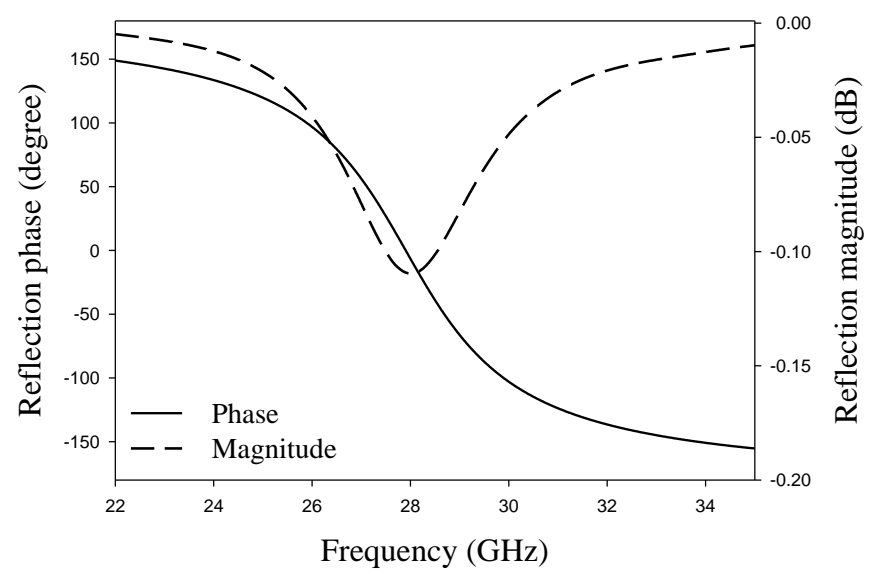

Fig. 6. Reflection phase and magnitude of AMC

Whereas, FSS was characterized by transmission and reflection coefficients. The transmission was almost zero meanwhile the reflection was $-50.22 \mathrm{~dB}$ at $28 \mathrm{GHz}$. Based on $-20 \mathrm{~dB}$, the frequency was laid between $23.08 \mathrm{GHz}$ to 31.85 $\mathrm{GHz}$, contributed to $31.32 \%$ of useful bandwidth.

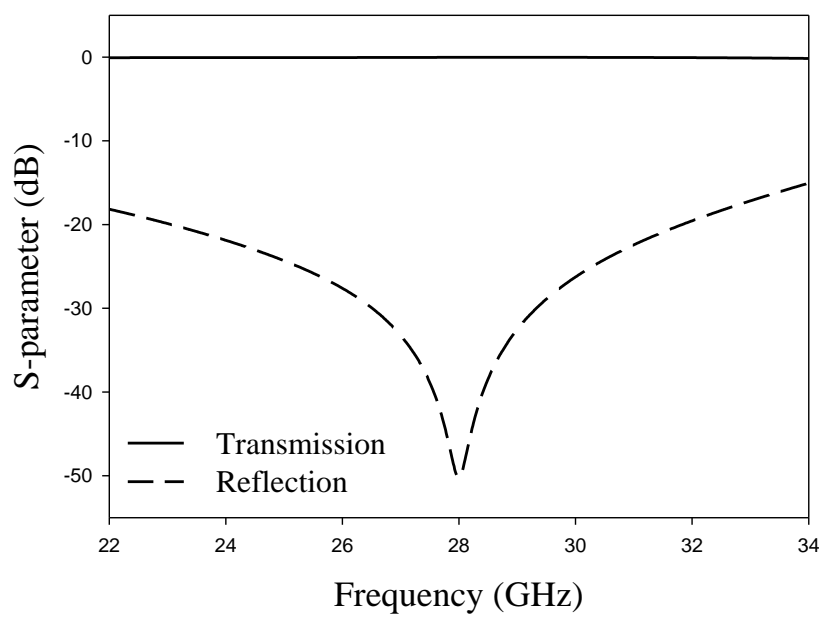

Fig. 7. Reflection and transmission coefficient of FSS

\section{Improvements of inset fed microstrip antenna}

Then, the inset fed microstrip antenna was incorporated with both of the metamaterials. All types of metamaterials were placed at the bottom of the antenna with no gap. Figure 8 shows the layers configuration of the antenna with types of metamaterials. Below was the four cases that being analyzed in this paper:

Case 1: The inset fed microstrip antenna

Case 2: The inset fed microstrip antenna with AMC

Case 3: The inset fed microstrip antenna with FSS

Case 4: The inset fed microstrip antenna with FSS-AMC

While Figure 9 shows the return loss for all cases both for simulation and measurement. In simulation, the resonating frequency of the antenna was shifted as incorporated with the metamaterials but still performed well at desired frequency. At $28 \mathrm{GHz}$, the return loss of the antenna was better for both case 3 and 4 as compared to case 1 . Increment of the useful bandwidth of the antenna around $0.31 \%, 4.64 \%$ and $0.64 \%$ for case 2, 3 and 4 respectively as compared to the antenna alone.

Therefore, the resonating frequency of the antenna for all cases were shifted to the lower frequency. Fortunately, the antenna operated well at $28 \mathrm{GHZ}$. The return loss of the antenna were $-12.38 \mathrm{~dB},-20.31 \mathrm{~dB},-30.01 \mathrm{~dB}$ and $-15.08 \mathrm{~dB}$ for all cases respectively. The useful bandwidth of the antenna was improved around $1.97 \%, 2.69 \%$ and $5.05 \%$ for case 2,3 and 4 as compared to case 1 . 


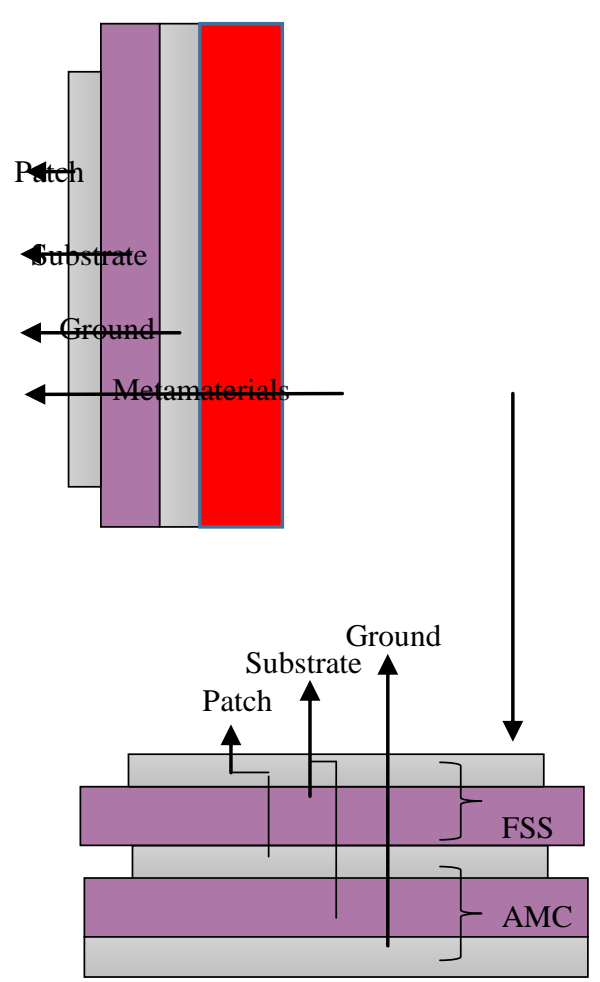

Fig. 8. Reflection and transmission coefficient of FSS
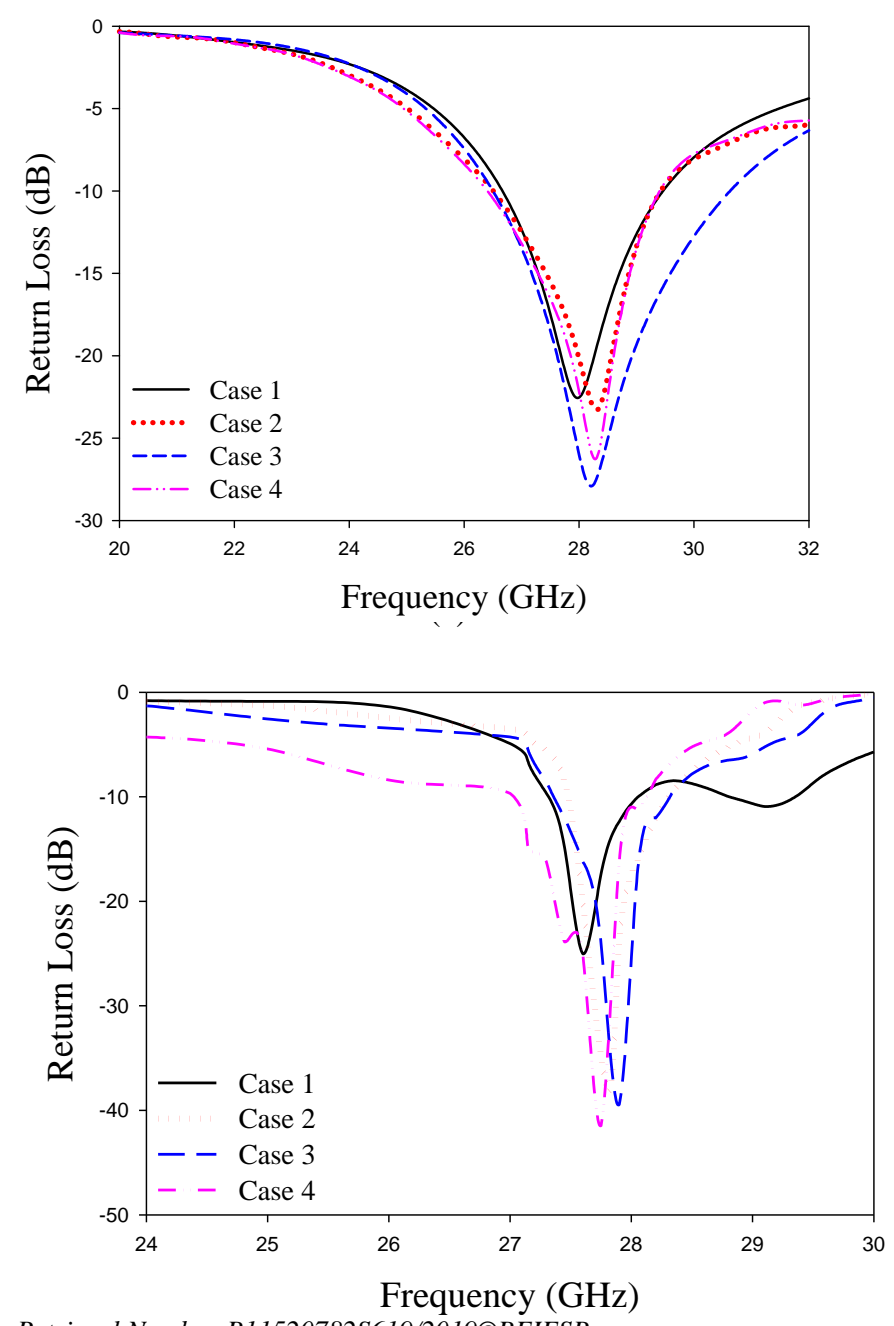

Retrieval Number:B11520782S619/2019@BEIESP (b)

Fig. 9. Return loss of inset fed microstrip antenna for all cases; (a) by simulation and (b) by measurement

Table 3 shows the improvements of the inset fed miscrostrip antenna at $28 \mathrm{GHz}$. The realized gain for the antenna alone was $3.76 \mathrm{~dB}$, with lowest improvement around $0.61 \mathrm{~dB}$ for case 3 , and highest boosted to $7.19 \mathrm{~dB}$ for case 4 . Proven that the incorporation with FSS-AMC leads the better improvements of the inset fed microstrip antenna.

Table III: Improvements of the antenna performances at $28 \mathrm{GHz}$

\begin{tabular}{|c|c|c|c|c|c|}
\hline & & Case 1 & Case 2 & Case 3 & Case 4 \\
\hline \multirow{2}{*}{$\begin{array}{c}\text { Return } \\
\text { loss (dB) }\end{array}$} & Sim & -22.34 & -20.46 & -25.09 & -23.19 \\
\cline { 2 - 6 } & Mea & -12.38 & -20.31 & -30.01 & -15.08 \\
\hline $\begin{array}{c}\text { Bandwidth } \\
(\%)\end{array}$ & Sim & 10 & 10.31 & 14.64 & 10.64 \\
\cline { 2 - 6 } & Mea & 0.72 & 2.69 & 3.41 & 5.77 \\
\hline $\begin{array}{c}\text { Realized } \\
\text { gain (dB) }\end{array}$ & & 3.76 & 5.91 & 4.37 & 7.19 \\
\hline
\end{tabular}

\section{CONCLUSION}

The insert feed microstrip antenna with types of types of metamaterials; AMC and FSS were successfully designed. The antenna and the metamatrials were printed on a thin substrate, Rogers RT5880 with $0.254 \mathrm{~mm}$ thickness. The metamaterials were placed on the bottom of the antenna with no gap. Four cases were analyzed; antenna alone, antenna with AMC, antenna with FSS and antenna with multi-layer of FSS-AMC. The resonating frequency was shifted but still operate well at $28 \mathrm{GHz}$. Improvements in useful bandwidth from antenna alone and as it worked with all types of metamaterials. The realized gain was effectively improved from $1.76 \mathrm{~dB}$ up to $6.16 \mathrm{~dB}$ for the fourth cases. The design of insert feed microstrip antenna with types of thin metamaterials can be applied as a flexible applications in advanced sensors.

\section{ACKNOWLEDGMENT}

The authors wish to thank the Ministry of Science, Technology and Innovation (MOSTI), Center for Research and Innovation Management (CRIM) and Zamalah Scheme of Universiti Teknikal Malaysia Melaka (UTeM) for the support of this work under the grant number PJP/2017/FKEKK/HI10/S01530.

\section{REFERENCES}

1. P. P. Punia, et al., "Inset Fed Rectangular Microstrip Patch Antenna for UHF Radio Frequency Identification," International Journal of Engineering Research \& Technology (IJERT), Vol. 4 (8), pp. 428-430, 2015.

2. N. T. Selvi, et al., "An Inset-Fed Rectangular Microstrip Patch Antenna with Multiple Split Ring Resonator Loading for WLAN and RF-ID Applications," Progress in Electromagnetics Research, Vol. 81, pp. 41-52, 2018.

Published By:

Blue Eyes Intelligence Engineering \& Sciences Publication 
3. V. Samarthay, et al., "Designing and Optimization of Inset Fed Rectangular Microstrip Patch Antenna (RMPA) for Varying Inset Gap and Inset Length," International Journal of Electronic and Electrical Engineering, Vol. 7 (9), pp. 1007-1013, 2014.

4. J. Singh, et al., "Inset Feed Microstrip Patch Antenna," International Journal of Computer Science and Mobile Computing, vol. 5(2), pp.324-329, 2016.

5. S. Mokha, et al., "Design of Flexible Micrstrip Patch Antenna of 2.4 GHz Operation Frequency using HFSS," International Research Journal of Engineering and Technology (IRJET), Vol. 3 (15), pp. 638-644, 2016.

6. J. Kurian, et al., "Flexible microstrip patch antenna using rubber substrate for WBAN applications, Wetness and Specific Absorption Rate Measurements," 2014 International Conference on Contemporary Computing and Informatics (IC3I), 2014.

7. E. Sidhu, et al., "Flexible microstrip patch antenna designs for Bluetooth, IMT, WLAN and WiMAX applications," 2017 Progress in Electromagnetics Research Symposium - Spring (PIERS), 2017.

8. R. Lakshmanan, et al., "Flexible Ultra Wide Band Antenna for WBAN Applications," International Journal of Applied Engineering Research. Vol. 24, 2016.

9. A. Kumar, et al., "Design Analysis of Different Types of Feed to Microstrip Patch Antenna," ICONIC Research and Engineering Journals, Vol. 1 (6), pp. 7-11, 2017.

10. A. Arora, et al., "Comparative study of different Feeding Techniques for Rectangular Microstrip Patch Antenna," International Journal Of Innovative Research in Electrical, Electronics, Instrumentation And Control Engineering, Vol. 3 (15), pp. 32-35, 2015.

11. D. M. Pozar, Microwave Engineering, Boston, MA, USA: Artech House, 1998.

12. V. Midasala et al., "Microstrip Patch Antenna Array Design to Improve Better Gains," International Conference on Computational Modeling and Security (CMS 2016), pp. 401-409, 2016.

13. S. Datto, et al., "Optimized Microstrip Patch Antenna (MPA) Array Design to Enhance Gain for S-Band Application," IOSR Journal of Electrical and Electronics Engineering (IOSR-JEEE), Vol. 12 (3), pp.74-78, 2017.

14. K. L. Nani, et al., " $1 \times 4$ Rectangular Patch Array Operating at $10 \mathrm{GHz}$ using Corporate Feeding Technique," International Journal of RF and Microwave Computer Aided Engineering, vol. 5 (2), pp.845-848, 2017.

15. S. Peddakrishna, et al., "Performance Improvement of Slotted Elliptical Patch Antenna using FSS Superstrate," International Journal of Applied Engineering Research. 2018.

16. A. S. Mekki, et al., "Gain Enhancement of a Microstrip Patch Antenna Using a Reflecting Layer," International Journal of Antennas and Propagation, 2014.

17. S. Karkari, et al., "Enhancing Return Loss of Rectangular Microstrip Antenna Using AMC," International Research Journal of Engineering and Technology (IRJET), Vol. 2 (4), pp. 1045-1048, 2015.

18. V. Ekke, et al., "Gain Enhancement of Microstrip Patch Antenna Array with AMC Structure Using Multilayer PCB Technology,” International Conference on Smart Trends for Information Technology and Computer Communications, pp. 632-639, 2016.

19. A. Chatterjee, et al., "Gain Enhancement of a Wide Slot Antenna Using a Second-Order Bandpass Frequency Selective Surface," Radio Engineering, Vol. 24 (2), pp. 455-461, 2015.

20. A. Ghish, et al., "Design f Triple Band Slot-Patch Antenna with Improved Gain using Triple Band Artificial Magnetic Conductor," Radio Engineering, Vol. 25 (3), pp. 455-461, 2015.

\section{AUTHORS PROFILE}

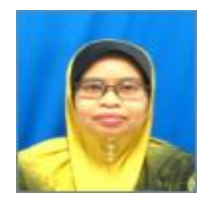

Maisarah Abu received her Bachelor Degree of Engineering in electrical engineering from Universiti Teknologi MARA in 2001. Then, she received her Master from Universiti Kebangsaan Malaysia in 2003. In 2012, she received her $\mathrm{PhD}$ from Universiti Teknologi Malaysia for her thesis on Dipole Antenna and Artifizial Magnetic Conductor for RFID Application. She was employed as a lecturer at Universiti Teknikal Malaysia Melaka since 2003. Now she is a Senior Lecturer with research interest of RF, Microwave and Antenna with Metamaterial (EBG, AMB, and FSS) and RFID.

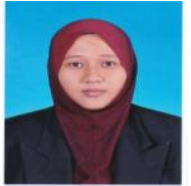

Siti Adlina Md Ali has received her Bachelor Degree in Electronic Engineering (Telecommunication) with honours in 2009 and Master of Science in Electronic Engineering in 2017 from Universiti Teknikal Malaysia Melaka. Now she is doing her Philosophy Degree (PhD) at Universiti Teknikal Malaysia Melaka, analyzing losses introduced by microwave absorber starting from 2018 .

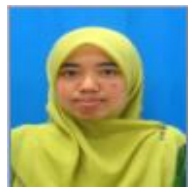

Siti Normi Zabri received her Bachelor Degree of Engineering in electrical engineering from Universiti Teknologi MARA in 2007. Then, she received her Master from The University of Sheffield in 2008. In 2015, she received her $\mathrm{PhD}$ from Queen's University of Belfast for her thesis on Study of Thin Resistively Loaded FSS based Microwave Absorbers. She was employed as a lecturer at Universiti Teknikal Malaysia Melaka with research interest of Frequency Selective Surface and Microwave Absorber.

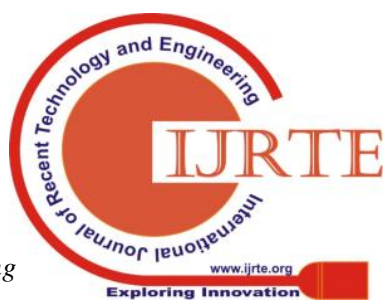

